\title{
Valve replacement in octogenarians: increased early mortality but good long-term result
}

\author{
M. Pasic, T. Carrel, A. Laske, E. Bauer, J. Turina*, R. Jenni ${ }^{*}$, L. von Segesser and M. Turina \\ Clinic for Cardiovascular Surgery and Department of Medicine*, University Hospital Zurich, Switzerland
}

\begin{abstract}
KEY WORDS: Octogenarian, aortic stenosis, aged, valvular surgery, valve replacement.
Between January 1983 and December 1990, 20 patients aged 80 years or older underwent valvular surgery. The patients' ages varied from 80 to 87 years (mean, $82 \pm 1.5$ years). The indication for operation was aortic stenosis in 19 patients, and mitral insufficiency after previous mitral valve replacement with a bioprosthesis in one. There were 15 elective, two urgent, and three emergency operations. Four of these patients had aortic valve replacement plus coronary artery bypass grafting. Six patients (30\%) had an uneventful hospital stay, and the other $14(70 \%)$ experienced several post-operative complications. The operative mortality rate was $15 \%$ (three patients). All patients before operation were in NYHA (New York Heart Association) class III and IV and all survivors remained in NYHA class I or II. The survivors have been followed from 6 to 70 months (mean $20 \pm 8$ months). The actuarial survival rate at 1 and 5 years was $78.5 \%$ and $67 \%$, respectively. Valvular replacement in octogenarians can be performed, despite the high rate of post-operative complications, with increased but acceptable mortality. Long-term results are good.
\end{abstract}

\section{Introduction}

Symptomatic medical treatment may do little to improve the condition of elderly patients with severe valvular heart disease. Once the symptoms of congestive heart failure develop, the quality of life deteriorates substantially ${ }^{[1]}$. In the past, these individuals were not offered valve replacement because of unacceptably high peri-operative mortality and morbidity. Recently, percutaneous ballon aortic valvuloplasty has emerged as an alternative to aortic valve replacement for management of aortic stenosis ${ }^{[2.3]}$. In this report, we assess the outcome of heart valve replacement in octogenarians at the Clinic of Cardiovascular Surgery of the University Hospital Zurich during a 7-year period.

\section{Patients and methods}

Between January 1983 and December 199020 patients aged 80 years or older underwent valve replacement procedures at the Clinic of Cardiovascular Surgery of the University Hospital, Zurich. All patients' records were reviewed to assess age, sex, diagnosis, risk factors, operative procedure, peri-operative complications, and long-term follow-up. Cardiac catheterization and echocardiography were performed in all patients. Narrowing of the left main coronary artery by more than $50 \%$ and narrowing of the other coronary arteries by more than $70 \%$ was considered sufficiently severe to warrant myocardial revascularization. All operations were performed with standard cardiopulmonary bypass in moderate hypothermia with intermittent cold cardioplegia and post-ischaemic warm blood cardioplegia since 1989.

Submited for publkation on 23 Apnl 199I, and in revised form 28 August 1991 .

Correpundence Dr Miralem Pasrc. Chinic for Cardiouascular Surgery, I nisersity Hospital Zunch, Racmistr. 100, CH-8091 Zunch, Switzerland.
Data are presented as simple percentage and frequency distributions. Values of continuous variables are expressed as mean \pm the standard deviation. Survival curves were calculated according to the method of Cutler-Ederer ${ }^{[4]}$.

\section{Results}

A total of 20 patients underwent valve replacement with or without coronary artery bypass grafting. One patient had mitral valve replacement after previous mitral valve replacement with a bioprosthesis, four had aortic valve replacement plus coronary artery bypass grafting, and 15 patients had aortic valve replacement alone. A porcine heterograft was placed in 16 patients (11 Carpentier-Edwards, 3 Xeno-Medica, and 2 IonescuShiley valves) and a mechanical prosthesis in the other four (three St. Jude Medical aortic, and one St. Jude Medical mitral). Enlargement of the annular area by Dacron patch was performed in four patients. Finally, in two patients a resection of the asymetric septal hypertrophy was performed.

Patients ages varied from 80 to 87 years (mean $82 \pm 1 \cdot 5$ years). There were 11 women and nine men. All patients had severe symptoms before operation that were refractory to aggressive medical therapy. All patients were in NYHA functional class III or IV before operation. Dyspnoea, angina, syncope, and heart failure were present in 20, nine, seven and seven patients, respectively. Two patients had a history of myocardial infarction, five hypertension, one diabetes mellitus, one neurovascular disease, three peripheral vascular disease, and one renal failure.

There were 15 elective, two urgent and three emergency operations. The indication for operation was aortic stenosis in 19 patients, and mitral insufficiency after previous mitral valve replacement with a bioprosthesis in one 


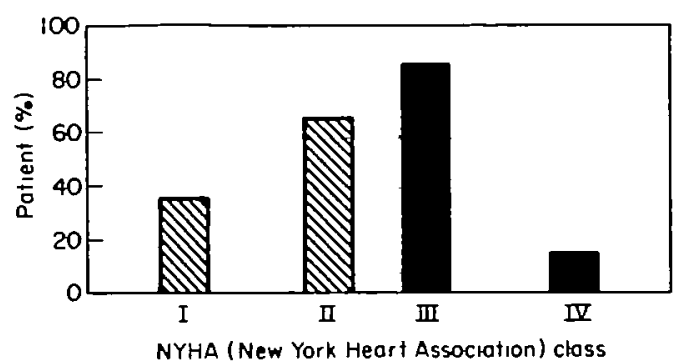

Figure 1 Bar graph of pre-operative ( $\square$ ) and postoperative $(\mathbb{\$})$ NYHA (New York Heart Association) functional classification.

patient. A mild aortic regurgitation was present in seven patients, and a mild mitral regurgitation in nine. Coronary artery disease was diagnosed in 11 cases: threevessel disease was found in three patients, two-vessel disease in four, and one-vessel disease in four patients. Left ventricular ejection fraction was $52 \pm 15 \%$ (range, 25 to $83 \%$ ).

The mean aortic valve gradient was $70 \pm 22 \mathrm{mmHg}$, the calculated aortic area in patients with aortic stenosis was $0.5 \pm 0.15 \mathrm{~cm}^{2}$, pulmonary capillary wedge pressure was $20 \pm 6 \mathrm{~mm} \mathrm{Hg}$, and right atrial pressure $5 \pm 2 \mathrm{mmHg}$. The cardipulmonary bypass time was $84 \pm 33 \mathrm{~min}$, and aortic cross-clamp time was $52 \pm 22 \mathrm{~min}$.

The operative mortality was $15 \%$ (three of 20 patients). One patient with coronary artery disease and preoperative ejection fraction of $25 \%$ died from acute myocardial infarction on the 6 th post-operative day after an initially uncomplicated course. Another patient with asymptomatic $70 \%$ and $80 \%$ bilateral significant carotid stenoses had developed cerebral insult and died from sepsis and multi-organ failure after aortic valve replacement and coronary artery bypass grafting to the right coronary artery. His ejection fraction was $31 \%$ pre-operatively. The third patient with unsignificant coronary artery disease had post-operative bleeding with haemorrhagic diathesis, he also died from acute myocardial infarction.

Six patients $(30 \%)$ had an uneventful hospital stay, and the others $14(70 \%)$ experienced several post-operative complications. Six patients had post-operative bleeding and had to be re-operated for control of bleeding (two patients twice). Ten patients had post-operative arrhythmias; respiratory failure was observed in four, respiratory infection in two, two patients developed a low cardiac output syndrome. Delirium was noted in three, mental confusion in one, and depression in one post-operatively. Two patients had cerebrovascular accident, and two sepsis. Three patients underwent tracheostomy and one gastrostomy for chronic care after severe post-operative complication.

At the end of follow-up (mean 22 months, range 6-70 months) all patients who survived were in NYHA functional class I or II (Fig. 1). All survivors had improved compared to their pre-operative status. During follow-up two patients died, one from myocardial infarction and the other from sudden death. The 1-year and 5-year actuarial survival rate was $78 \cdot 5 \pm 5 \%$ and $67 \pm 10 \%$ (Fig. 2).

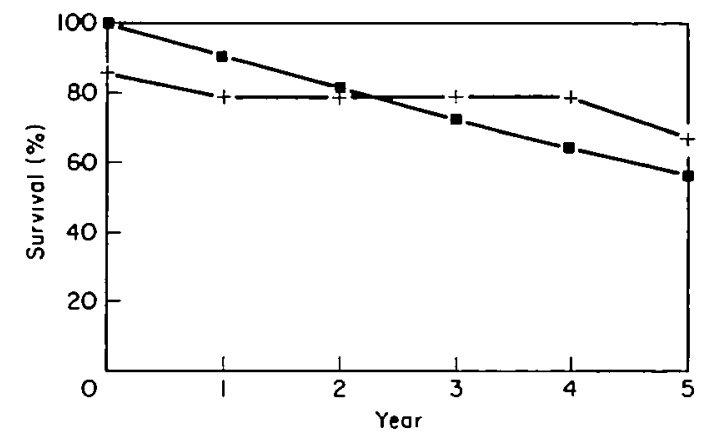

Figure 2 Actuarial survival of the whole group of 20 patients aged 80 years or older having valve replacement (the patients who died in hospital are included), and of the age- and sex-matched counterparts in the general Swiss population. $\mathbf{\square}=$ Swiss population; + postoperative.

\section{Discussion}

Our early mortality of $15 \%$ and 5 -year actuarial survival rate of $67 \%$ showed an elevated but acceptable risk in the octogenarian. Our report has confirmed the safety and efficacy of valve replacement in this advanced age group. Several studies have reported similar good results in elderly patients undergoing cardiac surgery ${ }^{[5-12]}$. The long-term survival curve of our patients is better than that of the general population (Fig. 2).

The benefits of percutaneous aortic valvuloplasty in the elderly are temporary, improving haemodynamic status for a few weeks or months ${ }^{[13.14]}$; morbidity and mortality is relatively high ${ }^{[15.16]}$. Percutaneous aortic valvuloplasty may provide a modest inprovement of survival as compared to the survival of untreated patients with significant aortic stenosis $^{[14.16]}$. It is a palliative procedure for a population of inoperable patients, but it is not an alternative to valve replacement $\mathrm{t}^{[12-14.16]}$.

The bioprosthetic valve is the safest cardiac valve substitute in the octogenarian. Because systemic anticoagulation is rarely required, bioprostheses have a reduced incidence of haemorrhagic and thrombotic complications than mechanical valves ${ }^{[1]}$.

Single-valve replacement combined with coronary artery bypass grafting resulted in a higher early and late mortality in octogenarians than in septuagenarians undergoing similar combined procedures ${ }^{[5.17]}$. This elevated mortality raises the question of the necessity of concomitant revascularization during valve replacement in the elderly. Conservatively, one may propose that, in octogenarians, only those with critical coronary lesions $(>80 \%)$ or severe angina should undergo concomitant coronary bypass grafting ${ }^{\{\xi\}}$. The aggressive approach requires prolonged ischaemic time and may not be appropriate in the octogenarian. This contrasts with the surgical principle for younger patients in whom revascularization should be performed at the time of valve replacement if major coronary artery stenosis is present regardless of the presence or absence of angina ${ }^{[18]}$.

In two patients we performed a resection of the asymmetric septal hypertrophy which had caused subvalvular aortic stenosis. This clearly dynamic obstruction 
represents an adaptive mechanism to the long-standing pressure or volume overload ${ }^{[19]}$. The policy of resection during aortic valve replacement is radical in our centre. In our experience it is safer to perform an immediate operative resection of asymmetric septal hypertrophy than to rely on massive doses of beta-blockers during periods of hypotension, which can occur when asymmetric septal hypertrophy is left unrelieved during aortic valve replacement ${ }^{[20]}$.

The operative risk is related to the procedure performed, as well as to the degree of cerebrovascular, renal, and respiratory impairment present pre-operatively ${ }^{[5,21]}$. Our report also confirmed a high incidence of postoperative complications in octogenarians. There is a tendency for patients to either have no complications or to have several together. The occurrence of pneumonia, respiratory failure, or both is associated with a poor outcome ${ }^{[6]}$. The interpretation of these observations seems clear: even in this generally healthy population of octogenarians, functional reserve is not great. A substantial proportion of such patients have a prolonged and complicated course, leading ultimately to a good outcome ${ }^{[?}$. Early mortality in our study was closely related to poor ventricular function and untreated concomitant diseases. Healthy octogenarians with severe aortic stenosis and good ventricular function should be considered as potential candidates for a surgical intervention.

These patients should be further selected as having a reasonable chance of surviving an operation. All concomitant diseases should be treated before or during the valve replacement. Each case should be judged on an individual basis, and decisions made by both the patient and doctor.

Although the rate of post-operative complications is high, heart valve replacement can be performed with moderate mortality in relatively healthy octogenarians. The improvement in functional capacity and the prolongation of late survival in our series justifies valve replacement in selected octogenarian patients. Advanced age itself should not be considered as a contraindication to surgery.

The authors gratefully thank the assistance of Miss Anette Bauer for help preparing the manuscript.

\section{References}

[I] O'Keefe JH, Vlietstra RE, Balley KR, Holmes DR. Natural history of candidates for balloon aortic valvuloplasty. Mayo Clin Proc 1987; 62: 986-91.
[2] Cribier A, Savin T, Saoudı N, Rocha B, Berland J, Letac B. Percutaneous translumınal valvuloplasty of acquired aortic stenosis in elderly patients: An alternatuve to valve replacement? Lancet 1986; 1. 63-7.

[3] Safian RD, Berman AD, Diver DJ et al. Baloon aortic valvuloplasty in 170 consecutive patients. N Engl J Med 1988, 319: 125-30.

[4] Cutler SJ, Ederer F. Minimum utilization of the life table method in analyzing survival. J Chron Dis 1958; 8: 699-712.

[5] Fiore AC, Naunheim KS, Barner HB et al. Valve replacement in the octogenarian. Ann Thorac Surg 1989; 48: 104-8.

[6] Levinson JR, Akins CW, Buckley MJ el al. Octogenanans with aortic stenosis. Outcome after aortic valve replacement Circulation 1989; 80 (Suppl I): 49-56.

[7] Pflug M, Turina M, Senning A. Der Aortenklapenersatz beim älteren Patienten. Schweiz med Wschr 1982; 112: 634-8.

[8] Studer M, Egloff L, Rothlin M, Turina M, Senning A. Herzchirurgie beım über 70 jährıgen Patienten. Schweiz med Wschr 1984; $114: 1589-93$.

[9] Bashour TT, Hanna ES, Myler RK et al. Cardiac surgery in patients over the age of 80 years. Clin Cardiol 1990; 13: 267-70.

[10] Naunheim KS, Dean PA, Fiore AC et al. Cardiac surgery in the octogenarian. Eur J Cardio-thorac Surg 1990; 4: 130-5.

[I I] Deleuze P. Loisance DY, Besnainou F el al. Severe aortic stenosis in octogenarians: is operation an acceptable alternative? Ann Thorac Surg 1990; 50: 226-9.

[12] Azariades M, Fessler CL, Ahmad A, Starr A. Aortıc valve replacement in patients over 80 years of age: a comparative standard for balloon valvuloplasty. Eur J Cardio-thorac Surg 1991; 5: 373-7.

[13] Chioin R, Ramondo A, Chirillo $F$ et al. Short-lasting hemodynamic and clinical benefits from percutaneous balloon valvuloplasty for calcific aortic stenosis. Jpn Heart J 1990; 31: 609-17.

[14] Dorros G, Shaw RE, Assa J et al. Percutaneous transluminal aortic valvuloplasty-the acute outcome and follow-up of 149 patients who underwent the double balloon technique. Eur Heart J 1990; $11 \cdot 429-40$.

[15] Bernard Y, Bassand JP, Anguenot $T$ et al. Aortic valve area evolution after percutaneous aortic valvuloplasty. A prospective trial using a combined Doppler echocardiographic and hemodynamic method. Eur Heart J 1990; 11: 98-107.

[16] O'Neil WW. Predictors of long-term survival after percutaneous aortic valvuloplasty: report of the Mansfield scientific balloon aortic valvuloplasty registry. J Am Coll Cardiol 1991; 17: 193-8.

[17] Borkon AM, Soule LM, Baughman KL. Aortic valve selection in the elderly patient. Ann Thorac Surg 1988; 46: $270-7$.

[18] Kouchoukos NT, Lell WA. Rogers WJ. Combined aortic valve replacement and myocardial revascularization. Ann Surg 1983: 197: 7217

[19] Hess OM, Schneider J, Turina M el al. Asymetric septal hypertrophy in patients with aortic stenosis: an adaptive mechanism or a coexistence of hypertrophic cardiomyopathy? J Am Coll Cardiol 1983; 1: 783-9.

[20] Turina M. Asymmetric septal hypertrophy should be resected during aortic valve replacement. Z Kardiol 1986; 75 (Suppl 2): 198-200.

[21] Fremes SE, Goldman BS, Ivanov J, Weisel RD, David Te, Salerno T. Valvular surgery in the elderly. Circulation $1989 ; 80$ (Suppl I): 7790. 